\title{
Enhanced Removal of Lead by Chemically and Biologically Treated Carbonaceous Materials
}

\author{
Mohamed E. Mahmoud, ${ }^{1}$ Maher M. Osman, ${ }^{1}$ Somia B. Ahmed, ${ }^{1}$ and Tarek M. Abdel-Fattah² \\ ${ }^{1}$ Department of Chemistry, Faculty of Sciences, Alexandria University, P.O. Box 426, Alexandria 21321, Egypt \\ ${ }^{2}$ Department of Molecular Biology and Chemistry Christopher Newport University, Christopher Newport University, \\ Newport News, VA 23606, USA
}

Correspondence should be addressed to Mohamed E. Mahmoud, memahmoud10@yahoo.com

Received 30 October 2011; Accepted 12 December 2011

Academic Editor: Amauri Antonio Menegário

Copyright (C) 2012 Mohamed E. Mahmoud et al. This is an open access article distributed under the Creative Commons Attribution License, which permits unrestricted use, distribution, and reproduction in any medium, provided the original work is properly cited.

\begin{abstract}
Hybrid sorbents and biosorbents were synthesized via chemical and biological treatment of active carbon by simple and direct redox reaction followed by surface loading of baker's yeast. Surface functionality and morphology of chemically and biologically modified sorbents and biosorbents were studied by Fourier Transform Infrared analysis and scanning electron microscope imaging. Hybrid carbonaceous sorbents and biosorbents were characterized by excellent efficiency and superiority toward lead(II) sorption compared to blank active carbon providing a maximum sorption capacity of lead(II) ion as $500 \mu \mathrm{mol} \mathrm{g}^{-1}$. Sorption processes of lead(II) by these hybrid materials were investigated under the influence of several controlling parameters such as $\mathrm{pH}$, contact time, mass of sorbent and biosorbent, lead(II) concentration, and foreign ions. Lead(II) sorption mechanisms were found to obey the Langmuir and BET isotherm models. The potential applications of chemically and biologically modifiedactive carbonaceous materials for removal and extraction of lead from real water matrices were also studied via a double-stage microcolumn technique. The results of this study were found to denote to superior recovery values of lead $(95.0-99.0 \pm 3.0-5.0 \%)$ by various carbonaceous-modified-bakers yeast biosorbents.
\end{abstract}

\section{Introduction}

Lead is one of the highly toxic heavy metals and widely characterized as the major source of water pollution. Lead is well recognized for direct and negative impact on the human health as well as biological organisms and ecological system $[1,2]$. Lead poisoning in humans causes severe damage to the kidney, nervous system, reproductive system, liver, as well as brain and causes illness or death. Severe exposure to lead has been connected with sterility, abortion, stillbirths, and neonatal death [3-5]. The permissible level for lead in drinking water is $0.05 \mathrm{ppm}$ according to the US Environmental Protection Agency (EPA). Therefore, the presence of very low concentration levels of lead in drinking water is considered as highly toxic and requires more efficient removal, extraction, and treatment methodologies [3].

A number of well-documented methods are known and reported in the literatures for potential applications in removal, extraction, separation, and preconcentration of lead from various water matrices as well as other environmental samples. These include precipitation, ion exchange, coagulation, floatation, reverse osmosis, membrane filtration, and solvent extraction [4]. Among these methods, adsorption is highly effective and economical one [5]. Silica gels, activated alumina, metal oxides and hydroxides, zeolites, clay minerals, synthetic polymers, and carbonaceous materials, such as activated carbon and molecular carbon sieves, were used as efficient sorbents for water treatments $[6,7]$.

The uses of carbonaceous sorbents for heavy metal removal from various matrices via adsorption were the subjects of a number of research papers. A comparative study of lead adsorption from aqueous solutions by raw and activated charcoals of Melocanna baccifera Roxburgh (bamboo) was reported [8]. Adsorption of lead from aqueous solutions onto a graphene layer ( $\mathrm{C} \pi$ electrons) by using activated 
carbon and charcoal was investigated and reported [9]. Sorption potential of impregnated charcoal for removal of lead and other heavy metals from phosphoric acid was reported [10]. Activated carbon was prepared from Enteromorpha prolifera (EP) by reaction with zinc chloride and the physicochemical properties were characterized by thermal stability, zeta potential, and Boehm titration methods [11]. Kinetics, isotherms, $\mathrm{pH}$, and ionic strength studies of $\mathrm{Pb}$ (II) sorption on activated carbon prepared from Polygonum orientale Linn were reported [12]. Batch sorption dynamics and equilibrium for removal of lead ions from aqueous phase using activated carbon developed from coffee residue activated with zinc chloride were also studied and evaluated [13]. A study was presented for the removal of lead(II) from wastewater by activated carbon developed from Tamarind wood by zinc chloride activation [14]. Studies on the removal of $\mathrm{Pb}(\mathrm{II})$ from wastewater by activated carbon developed from Tamarind wood activated with sulfuric acid was also reported [15]. Removal of copper(II) and lead(II) ions from aqueous solutions by adsorption on activated carbon from a new precursor hazelnut husks was developed [16]. Palm shell activated carbon was used as a good adsorbent for removal of lead from aqueous solutions [17]. Kinetics and equilibrium adsorption studies of lead(II) onto activated carbon prepared from coconut shell were reported [18]. A two-site adsorption model was used to describe the kinetics of adsorption and desorption of $\mathrm{Pb}$ (II) in aqueous solution on activated carbon [19]. Selective adsorption of lead on novel modified active carbons and marine algal biomass was presented [20]. Carbon nanotubes (CNTs) were used as adsorbent for study and evaluation of the adsorption thermodynamic, kinetic, and desorption studies of $\mathrm{Pb}^{2+}$ [21]. On the other hand, removal and extraction of lead and other heavy metals from different matrices were also accomplished by the use of various adsorbents [22-25].

Hybrid biosorbents are recently reported by several research works and these types of combined solid materials are characterized by incorporation of various metal binding and chelating characteristics from multicombined species [26-28]. Hybrid carbon biosorbents can be prepared by surface enhancement of the carbonaceous materials such as activated carbon or modified activated carbon with other chelating functional groups in certain biological components for the formation of new hybrid biosorbents. Recently, baker's yeast, known as Saccharomyces cerevisiae, was surface immobilized on silica gel, Dowex anion exchanger and other solid supports are successfully used as efficient biosorbents for removal of heavy metal ions such as $\mathrm{Cr}(\mathrm{III}), \mathrm{Cr}(\mathrm{VI})$, $\mathrm{Hg}(\mathrm{II}), \mathrm{As}(\mathrm{III})$, and As(v) from various matrices [26-32].

Removal of $\mathrm{Pb}(\mathrm{II})$ from industrial effluents by conventional treatment methods is commonly experienced with major problems and high difficulties in treating such wastewaters due to the matrix effect. Therefore, our purpose of this study is aimed at development of an effective and lowcost hybrid biosorbents for sorption, removal, extraction, and treatment of lead from water samples via immobilization of low-cost baker's yeast, as a source of chelating functional groups on oxidized-reduced activated carbon sorbents. The metal-biosorbent interaction processes and mechanisms were aimed to investigate and explore in this study via monitoring, evaluation, and optimization of the various experimental conditions as well as all controlling factors such as medium $\mathrm{pH}$, reaction contact time, sorbent dose, initial lead ion concentration, and interfering ions on the sorption capability.

\section{Experimental Section}

2.1. Chemicals and Solutions. Powder commercial active carbon was purchased from Adwic Chemicals, Egypt, and used as received. Baker's yeast was purchased from Starch and Yeast Co., Alexandria, Egypt. Nitric acid, acetic acid, sodium acetate trihydrate, lead(II) acetate trihydrate are all of analytical grade and purchased from Aldrich Chemical Company, USA, and other metal salts were purchased from BDH Limited, Poole, England.

Buffer solutions ( $\mathrm{pH}$ 1.0, 2.0, 3.0, 4.0, 5.0, 6.0, and 7.0) were prepared from 1.0 M hydrochloric acid solution and $1.0 \mathrm{M}$ sodium acetate trihydrate solution by mixing the appropriate volumes of the two solutions and diluting to 1.0 L. The $\mathrm{pH}$ value of resulting solutions was adjusted by a $\mathrm{pH}$ meter. The metal ion solutions were prepared from doubly distilled water (DDW).

\subsection{Instrumentation. A Shimadzu Fourier Transform in-} frared spectrophotometer (FT-IR system-BX 0.8009) was used in the range $200-4000 \mathrm{~cm}^{-1}$ to acquire the FT-IR spectra of activated carbon, active carbon-modified-baker's yeast, oxidized active carbon, oxidized active carbon-modifiedbaker's yeast, reduced active carbon, and reduced active carbon-modified-Baker's yeast adsorbents. These sorbents were also imaged by the use of scanning electron microscope (JSM-5300, JEOL Ltd.). An ion sputtering coating device (JEOL-JFC-1100E) was used to coat the SEM specimens with gold to increase the conductivity. The $\mathrm{pH}$ measurements of buffer and metal ion solutions were carried out by using an Orion $420 \mathrm{pH}$-meter calibrated against standard buffer solutions of $\mathrm{pH} 4.0$ and 9.2. $\mathrm{Pb}$ (II) concentration in various samples was determined by Shimadzu model AA6650 atomic absorption spectrophotometer at the specified wavelength.

\subsection{Synthesis of Hybrid Oxidized-Reduced Active Carbon-} Modified-Baker's Yeast Biosorbents. A sample of $75.0 \mathrm{~g}$ of commercial activated carbon was weighed and transferred to a $2.0 \mathrm{~L}$ beaker. $1.0 \mathrm{~L}$ of $\mathrm{HNO}_{3}(2: 1 \mathrm{v} / \mathrm{v}$ ratio $)$ used as an oxidizing agent was added and the reaction mixture was stirred for $4 \mathrm{~h}$. Oxidized active carbon was filtrated, washed with distilled water, and dried at $100^{\circ} \mathrm{C}$ to produce sorbent (Ox-AC). $25.0 \mathrm{~g}$ of $(\mathrm{Ox}-\mathrm{AC})$ sorbent was weighed and mixed with $50.0 \mathrm{~g}$ of baker's yeast and the reaction mixture was mixed well in presence of $50.0 \mathrm{~mL}$ of DDW. The oxidized active carbon-modified-baker's yeast biosorbent (Ox-ACBY) was left to dry in an oven at $60^{\circ} \mathrm{C}$ for $24 \mathrm{hrs}$. Reducedactive carbon (Rd-AC) sorbent was also prepared in a similar way. A sample of $75.0 \mathrm{~g}$-active carbon was weighed and added to $1.0 \mathrm{~L}$ of $\mathrm{Na}_{2} \mathrm{SO}_{3}$ solution (1.0 Molar) and the reaction mixture was stirred for $4 \mathrm{~h}$. Reduced active carbon was 
TABLE 1: Hybrid chemically and biologically modified-active carbon biosorbents.

\begin{tabular}{ll}
\hline Symbol & Sorbent \\
\hline AC & Active carbon \\
Ox-AC & Oxidized active carbon by nitric acid \\
Rd-AC & $\begin{array}{l}\text { Reducing active carbon by sodium sulfite } \\
\text { Oxidized active carbon by nitric acid and } \\
\text { modified by baker's yeast }\end{array}$ \\
Rd-AC-BY & $\begin{array}{l}\text { Reducing active carbon by sodium sulfite and } \\
\text { modified by baker's yeast }\end{array}$ \\
\hline
\end{tabular}

filtrated, washed with distilled, water and dried at $100^{\circ} \mathrm{C}$ to produce Rd-AC sorbent. $25.0 \mathrm{~g}$ of Rd-AC sorbent was weighed and mixed with $50.0 \mathrm{~g}$ of baker's yeast and the reaction mixture was mixed well in presence of $50 \mathrm{~mL}$ of DDW. The reduced active carbon-modified-Baker's yeast (Rd-AC-BY) was left to dry in an oven at $60^{\circ} \mathrm{C}$ for $24 \mathrm{hrs}$. The list and specifications of all hybrid chemically and biologically modified active carbon biosorbents are given in Table 1.

\subsection{Lead Sorption in Various Controlling Experimental Factors}

2.4.1. Effect of $p H$. Batch equilibrium technique was used to determine the metal sorption capacity values $\left(\mu \mathrm{mol} \mathrm{g}^{-1}\right)$ of oxidized-reduced active carbon-modified-baker's yeast biosorbents [33]. In this method, $100 \pm 1 \mathrm{mg}$ of dry biosorbent was weighed and added to a mixture of $1.0 \mathrm{~mL}$ of $0.1 \mathrm{M} \mathrm{Pb}(\mathrm{II})$ and $9.0 \mathrm{~mL}$ of the selected buffer solution ( $\mathrm{pH} 1.0-7.0$ ) in a $50 \mathrm{~mL}$ measuring flask and this reaction mixture was shaken at room temperature for $30 \mathrm{~min}$ by an automatic shaker. After equilibration, the mixture was filtered and washed three times with $100 \mathrm{~mL}-\mathrm{DDW}$. The unbounded metal ion was subjected to complexometric titration using $0.01 \mathrm{M}$-EDTA solution or by atomic absorption spectrophotometric analysis.

2.4.2. Effect of Contact Time. Batch equilibrium technique was also used and applied to study the effect of shaking time intervals $(1,5,10,15,20,25$, and $30 \mathrm{~min})$ on the metal sorption capacity and extraction percentage values of lead according to the following procedure [34]. A sample of dry sorbent, $50 \pm 1 \mathrm{mg}$, was added to a mixture of $1.0 \mathrm{~mL}$ of $0.1 \mathrm{M}$ of $\mathrm{Pb}$ (II) and $9.0 \mathrm{~mL}$ of the selected buffer solutions $(\mathrm{pH} 2.0$ and 7.0). This mixture was shaken for the selected period of time, filtered, washed with $100 \mathrm{~mL}$ DDW, and the unextarcted metal ion was determined.

2.4.3. Effect of Biosorbent Dose. The effect of biosorbent dose $(25,50,100,250$, and $500 \mathrm{mg})$ was also studied by the batch equilibrium technique. A mixture of $1.0 \mathrm{~mL}$ of $0.1 \mathrm{M} \mathrm{Pb}(\mathrm{II})$ and $9.0 \mathrm{~mL}$ of buffer solution $(\mathrm{pH} 7.0)$ was added to the selected sorbent dose into a $50.0 \mathrm{~mL}$ measuring flask. These were then shaken at room temperature for 30 minutes by an automatic shaker. After equilibration, the mixture was filtered and washed three times with $100.0 \mathrm{~mL}-\mathrm{DDW}$.
2.4.4. Effect of Initial Lead Concentration. Batch equilibrium process was used to determine the effect of different concentrations of lead on the sorption capacity values. In this method, $100 \pm 1 \mathrm{mg}$ of the dry biosorbent was weighed and added to a mixture of $1.0 \mathrm{~mL}$ of different metal ion concentrations $(0.010,0.025,0.050,0.100,0.250$, and $0.500 \mathrm{M}$ ) and $9.0 \mathrm{~mL}$ of the selected buffer solution $(\mathrm{pH}$ 7.0 ) in a $50.0 \mathrm{~mL}$ measuring flask. The reaction mixture was shaken at room temperature for $30 \mathrm{~min}$ by an automatic shaker. After equilibration, the mixture was filtered and washed three times with $100.0 \mathrm{~mL}$ DDW.

2.4.5. Effect of Interfering Ions. The same procedures were also used to evaluate the effect of foreign ions on metal sorption capacity values of $\mathrm{Pb}$ (II) by oxidized-reduced carbon-modified-Baker's yeast biosorbents. A sample of dry biosorbent, $100 \pm 1 \mathrm{mg}$, was added to a mixture of $1.0 \mathrm{~mL}$ of $0.1 \mathrm{M}$ of $\mathrm{Pb}(\mathrm{II})$ and $1.0 \mathrm{~mL}$ of $0.1 \mathrm{M}$ of the selected foreign solution $\left(\mathrm{KNO}_{3}, \mathrm{NaCl}, \mathrm{CoCl}_{2}, \mathrm{Ni}(\mathrm{OAc})_{2}\right.$, and $\left.\mathrm{CuCl}_{2}\right)$ and $9.0 \mathrm{~mL}$ of the optimum buffer solution. This mixture was shaken for $30.0 \mathrm{~min}$, filtered, washed with $100 \mathrm{~mL}$ DDW, and the unextarcted metal ion was determined.

2.5. Potential Applications of Hybrid Active Carbon Biosorbents for Removal of Pb(II) From Water Samples. Removal and extraction of lead species from various water samples were performed according to the following procedure [35]. Real water samples (Alexandria drinking tap water and agricultural waste samples) were collected and a $1.0 \mathrm{~L}$ of each sample was spiked with $\sim 1-2 \mathrm{ppm}$ of $\mathrm{Pb}$ (II). A multistage microcolumn system was used and applied to evaluate the efficiency of hybrid active carbon biosorbents for solid-phase extraction of $\mathrm{Pb}$ (II) from real water matrices via multistage microcolumn technique. Each column stage was packed with $200 \pm 1 \mathrm{mg}$ of the selected sorbent and water sample was passed with a flow rate of $10 \mathrm{~mL} \mathrm{~min}^{-1}$ under air pressure. Effluent solution was collected, acidified with nitric acid, and subjected to atomic absorption spectrophotometric analysis of the free unextracted $\mathrm{Pb}(\mathrm{II})$. Real water samples were also subjected for atomic absorption spectrophotometric analysis before running over the column.

\section{Results and Discussion}

3.1. Surface Characterization. Surface functionality of carbon sorbents is characterized by its responsibility for all activity and reactivity as well as capability for all adsorption properties and processes. In this work, infrared spectroscopy was used to obtain information about the chemical structure and functional groups of the raw material and the hybrid activated carbon biosorbents. The FTIR spectrum represented in Figure 1(a) is showing few characteristic peaks that are mainly related to the organic nature of $\mathrm{AC}[36,37]$. However, upon redox treatments of $\mathrm{AC}$, these peaks were intensified and other new IR peaks were produced. A peak centered at $1110-1120 \mathrm{~cm}^{-1}$ is mainly due to $v(\mathrm{C}-\mathrm{O})$ of methoxy group. The strong bands appearing at 1520 and $1670 \mathrm{~cm}^{-1}$ are ascribed to the formation of oxygen functional groups based on highly conjugated $\mathrm{C}=\mathrm{O}$ stretching in 


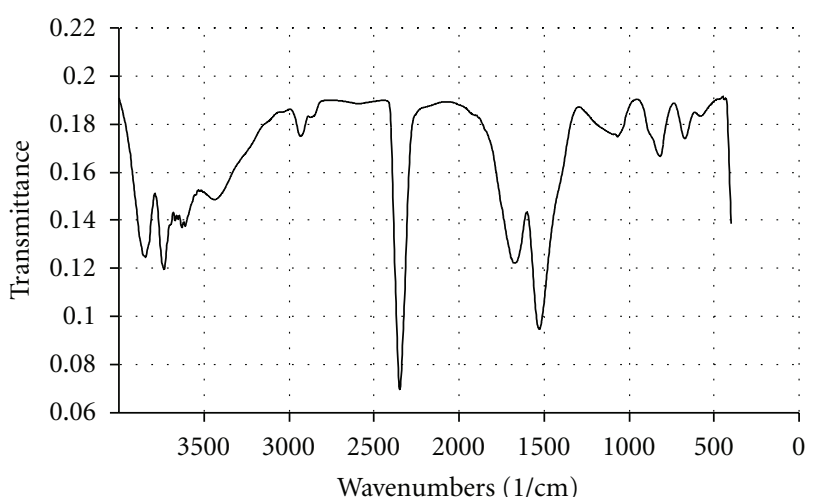

— Somaia 6 edit.sp

(a) FT-IR spectrum of AC sorbent

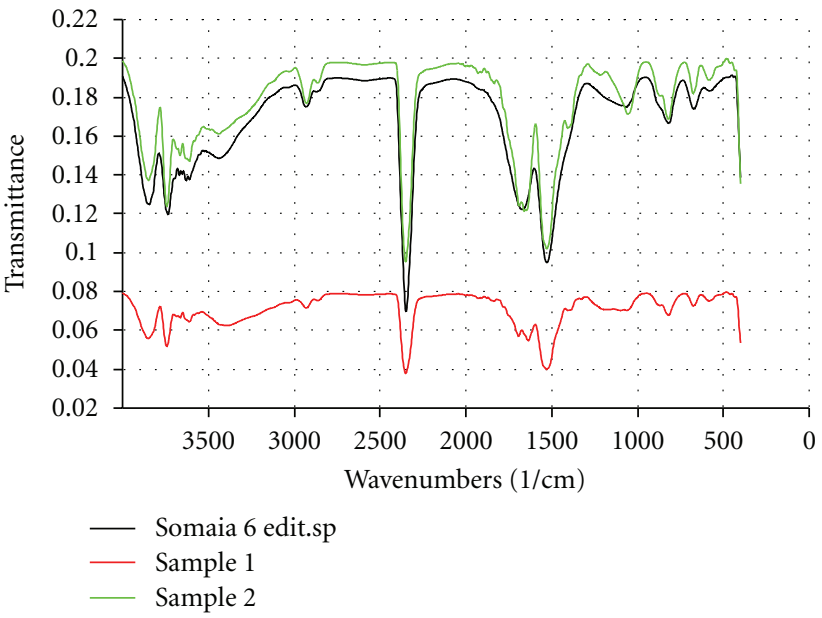

(c) FT- IR spectrum of Ox-AC-BY biosorbent



(b) FT-IR spectrum of Ox-AC sorbent



$\begin{array}{ll}\text { — Somaia } 6 \text { edit.sp } & \text { - Sample } 2 \\ \text { Sample } 1 & \text { Sample } 3\end{array}$

(d) FT-IR spectrum of Rd-AC sorbent

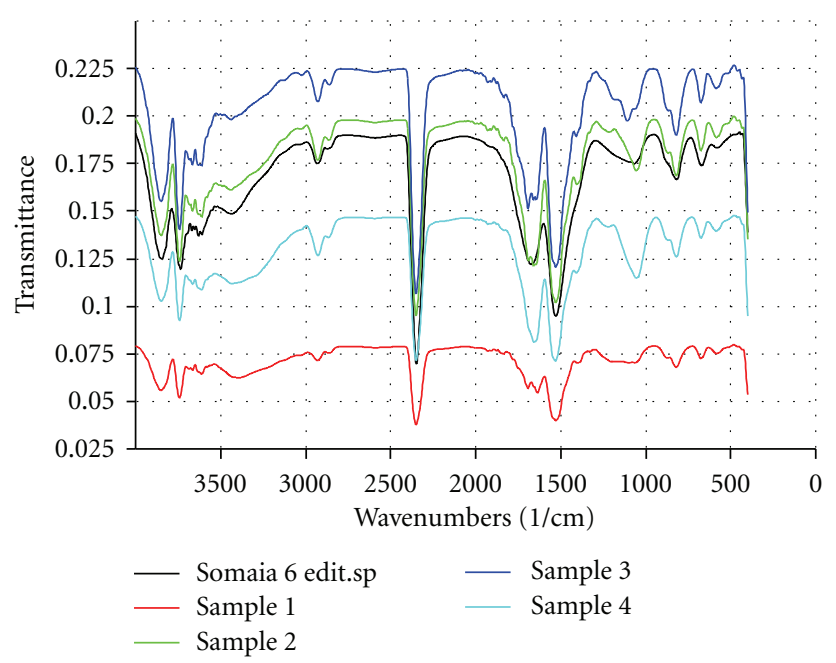

(e) FT-IR spectrum of Rd-AC-BY biosorbent

FIGURE 1: FT-IR spectra of various chemically and biologically treated carbonaceous sorbents.

carboxylic or carboxylate group as well as carbonyl group. A band was observed at $2860 \mathrm{~cm}^{-1}$ and ascribed to the presence of aliphatic compounds. A broad band in the region 3300$3600 \mathrm{~cm}^{-1}$ is typically attributed to $v \mathrm{O}-\mathrm{H}$ stretching or adsorbed water molecule [37]. Thus, redox treatment process of AC-surface is important in improving and intensifying the various functional groups of AC sorbent. The FT-IR spectra of Ox-AC-BY and Rd-AC-BY biosorbents were also found to 
TABLE 2: Sorption capacity values of lead by modified active carbon sorbents in various buffer solutions.

\begin{tabular}{lccccc}
\hline $\mathrm{pH}$ & \multicolumn{4}{c}{ Metal sorption capacity $\left(\mu \mathrm{mol} \mathrm{g}^{-1}\right)$} & in various buffer solutions* \\
& AC & Ox-AC & Rd-AC & Ox-AC-BY & Rd-AC-BY \\
\hline 1 & 20 & 40 & 30 & 200 & 190 \\
2 & 30 & 90 & 100 & 256 & 225 \\
3 & 50 & 100 & 135 & 345 & 230 \\
4 & 60 & 105 & 170 & 400 & 245 \\
5 & 90 & 125 & 190 & 405 & 300 \\
6 & 90 & 135 & 280 & 440 & 340 \\
7 & 80 & 200 & 280 & 500 & 390 \\
\hline
\end{tabular}

${ }^{*}$ Values are based on $n=3$ with standard deviation of $2.0-4.0 \%$.

exhibit the same characteristic peaks of $\mathrm{AC}$ as well as some functional groups that are related to the yeast structure as previously reported [36].

Scanning electron microscopy (SEM) is a useful and efficient technique in evaluation of the surface morphology. Figure 2(a) is the SEM-image taken for blank AC sorbent. Figures 2(b) and 2(c) are the SEM images of oxidized $\mathrm{AC}$ sorbent $(\mathrm{Ox}-\mathrm{AC})$ and reduced $\mathrm{AC}$ sorbents (Rd-AC), respectively. It is clear from these two images that the surfaces of both sorbents have been changed due to itching by oxidizing-reducing treatments. However, the particles have retained their original shapes and distribution. On the other hand, biological treatment of $\mathrm{Ox}-\mathrm{AC}$ and $\mathrm{Rd}-\mathrm{AC}$ with baker's yeast for the formation of Ox-AC-BY and Rd-AC-BY biosorbents, respectively, has resulted in pronounced surface changes of these two biosorbents. One can easily identify that biologically modified sorbents are existing in aggregate particles of Ox-AC and Rd-AC combined and coated with baker's yeast as evident from the SEM images and given in Figures 2(d) and 2(e).

\subsection{Sorption Studies of Lead by Modified Active Carbon Sorbents}

3.2.1. Effect of $p H$. The effect of $\mathrm{pH}$ of tested metal ion solutions on the amount extracted by the modified-activated carbon sorbents and biosorbents is considered as one of the most important controlling factor in such procedure because of the liability of most metal ions to be strongly influenced by modified activated carbon biosorbents at certain $\mathrm{pH}$ values. Metal capacity $\left(\mathrm{MC}_{t}\right)$ values at any time, expressed in $\mu \mathrm{mol} / \mathrm{g}$, can be calculated from (2):

$$
\mathrm{MC}_{t}=\left[\frac{\left(C_{o}-C_{t}\right) V_{\mathrm{mL}}}{\text { Mass }_{\mathrm{g}}}\right] \times 1000
$$

where $C_{o}$ and $C_{t}$ are the initial and final metal ion concentrations in solution expressed in $\mathrm{mol} \mathrm{L}^{-1} \cdot V_{m L}$ is the volume of metal ion solution expressed in $\mathrm{mL}$, and Mass $\mathrm{g}$ is the mass of sorbent or biosorbent expressed in gram. It is important to compare the identified metal sorption capacity values of modified active carbon sorbents with those determined for blank active carbon (AC). Table 2 compiles the determined metal sorption capacity values, expressed in $\mu \mathrm{molg}^{-1}$ for $\mathrm{Pb}$ (II) under the effect of various buffer solutions ( $\mathrm{pH}$ 1.0-7.0). It is evident from the listed data that $\mathrm{AC}$ is the lowest sorbent in interaction with lead under the effect of all tested buffer solutions. The maximum capacity value was found as $90 \mu \mathrm{mol} \mathrm{g}^{-1}$ in buffer solutions with $\mathrm{pH}$ 5.0-6.0. However, treatment of active carbon by using nitric acid as an oxidizing agent for the formation of (Ox-AC) sorbent was found to increase the tendency and efficiency for lead removal in all studied acidic and neutral solutions. The maximum determined sorption capacity value was detected as $200 \mu \mathrm{mol} \mathrm{g}^{-1}$ in neutral buffer solution with $\mathrm{pH}$ 7.0. In the same fashion, the metal sorption capacity of treated active carbon sorbent with sodium sulfite as a reducing agent for the formation of (Rd-AC) was also found to increase and reach a value of $280 \mu \mathrm{mol} \mathrm{g}^{-1}$ in buffer solutions with $\mathrm{pH}$ 6.0-7.0.

Further surface modification of AC, Ox-AC, and RdAC sorbents via loading of baker's yeast to produce the corresponding hybrid carbon biosorbents AC-BY, Ox-AC$\mathrm{BY}$, and Rd-AC-BY, respectively, were studied and compared for lead binding and sorption interaction processes. The determined metal capacity values are also listed in Table 2. It is evident from the given data that baker's yeast played a significant role in improving the sorption capacity values of all tested sorbents and biosorbents. A noticeable high increase in $\mu \mathrm{mol} \mathrm{g}^{-1}$ values is evident due to the presence of surface loaded yeast for AC-BY, Ox-AC-BY, and Rd-ACBY in all examined buffer solutions. A gradual increase from 370 to 390 and $500 \mu \mathrm{mol} \mathrm{g}^{-1}$ in the sorption capacity values of lead is evident by AC-BY, Ox-AC-BY, and Rd-ACBY biosorbents, respectively, referring to the contribution of both hybrid chemical and biological treatments of AC. Among all studied and evaluated chemically and biologically treated active carbon sorbents, Ox-AC-BY stands as the highest biosorbent in lead sorption and uptake with a sorption capacity value of $500 \mu \mathrm{mol} \mathrm{g}^{-1}$ in buffer solutions with $\mathrm{pH}$ 7.0.

\subsubsection{Effect of Shaking Time on the Metal Sorption Capacity.} The effect of shaking time is the second most important factor when batch or static technique is used in the processes of metal sorption capacity determination by newly synthesized sorbent or biosorbents. The results of this study are compiled in Table 3 and the values are expressed in $\mu \mathrm{mol} \mathrm{g}^{-1}$ as well as 


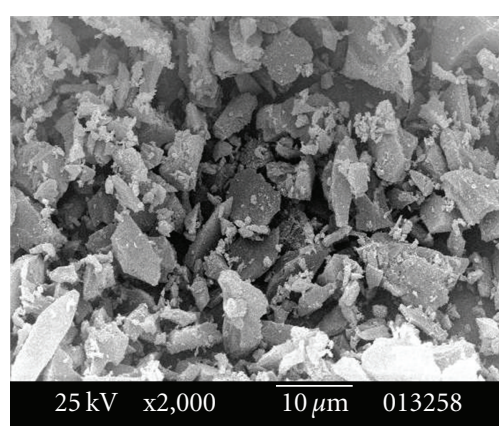

(a) SEM-Image of AC sorbent

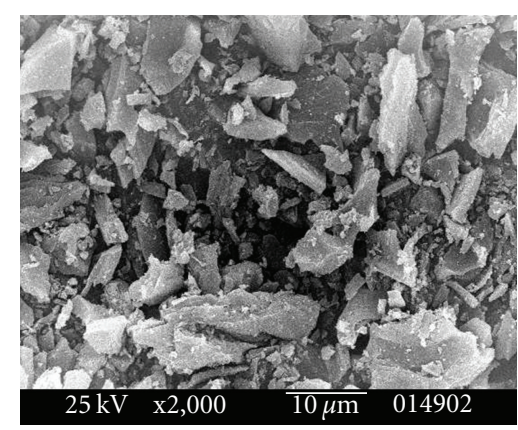

(b) SEM-Image of Ox-AC sorbent

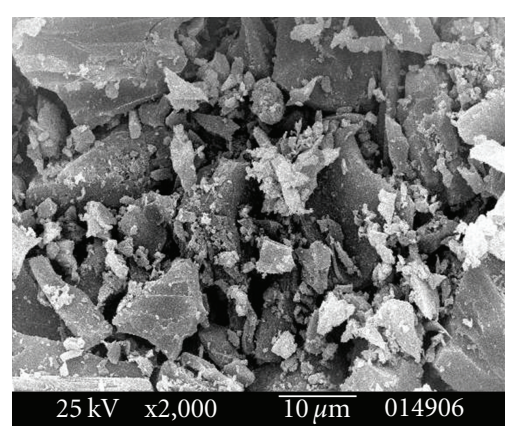

(c) SEM-Image of Rd-AC sorbent

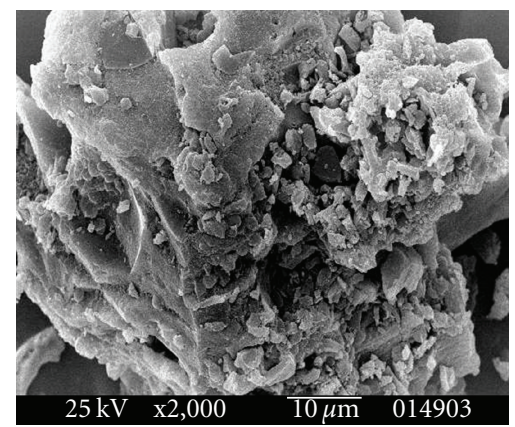

(d) SEM-Image of Ox-AC-BY biosorbent

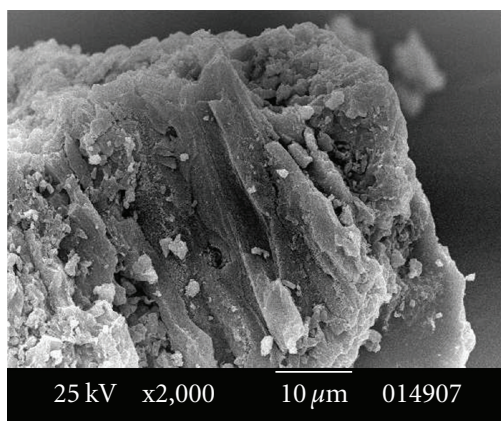

(e) SEM-Image of Rd-AC-BY biosorbents

FIGURE 2: SEM-images of various hybrid chemically and biologically treated sorbents and biosorbents.

percent extraction. It is clear from the data listed in Table 3 that a $100.0 \%$ extraction of $\mathrm{Pb}(\mathrm{II})$ by $\mathrm{Ox}-\mathrm{AC}$ and $\mathrm{Rd}-\mathrm{AC}$ sorbents was obtained after only 20 minutes of shaking time in $\mathrm{pH}$ 2.0. On the other hand, immobilization of baker's yeast on the surface of both Ox-AC and Rd-AC sorbents for the formation of Ox-AC-BY and Rd-AC-BY biosorbents was found to slow down the sorption of lead. This trend is mainly due to the presence of excessive amount of surface active groups from both active carbon as well as yeast functional groups that are capable of sorption and interaction with lead. Therefore, a gradual increase in the percent extraction of lead by Ox-AC-BY and Rd-AC-BY biosorbents is evident in Table 3.

$\mathrm{Ox}-\mathrm{AC}$ and $\mathrm{Rd}-\mathrm{AC}$ sorbents were found to require 25 minutes to give a $100.0 \%$ extraction of lead. Ox-AC-BY and Rd-AC-BY biosorbents were characterized by their strong affinity for binding with lead in buffer solution ( $\mathrm{pH} 7.0$ ) and attaining their $100.0 \%$ extraction also at 30 minutes of shaking time. This trend indicates that higher $\mathrm{pH}$ values are the optimum solution for these four sorbents and biosorbents. Finally, the effect of shaking time was also compared with the results of active carbon-modified-baker's yeast AC-BY. AC-BY and were found to similarly behave toward lead sorption in both buffer solutions, $\mathrm{pH} 2.0$ and 7.0. High percentage extraction values, 93.5 and $86.1 \%$, were identified by this sorbent after 1.0 minute shaking time in $\mathrm{pH}$ 2.0 and 7.0, respectively. A $100.0 \%$ extraction of lead in both buffer solutions was obtained after 20.0 minutes of shaking time. Thus, one can conclude from the effect of contact reaction time that the presence of surface loaded baker's yeast on chemically treated active carbon and higher buffer solutions are all working together to favor fast equilibrium, interaction, and sorption of lead.

3.2.3. Effect of Lead Concentration. The study of sorption equilibrium isotherms is essential in supplying the required basic information for the design and operation of sorption equipments for wastewater treatment. Various isotherm models including Langmuir, Freundlich, and BET models have been investigated and evaluated to describe and predict the sorption isotherms. The objective of this section is to study the sorption of lead(II) ions from aqueous solutions onto modified activated carbon sorbents and biosorbents. Under these three models, an equilibrium condition must be established and a relationship exists between the concentration of the solution interacting species and the sorbed species. Langmuir adsorption model is based on assuming that the adsorptive forces are similar to the forces in chemical interaction. The Langmuir equation in the linearized form is given by (2):

$$
q_{e}=\frac{1}{q_{\max }}+\frac{1}{q_{\max } K_{\mathrm{L}}} C_{e}
$$

where $q_{e}(\mathrm{mg} / \mathrm{g})$ is the equilibrium surface sorbed $\mathrm{Pb}(\mathrm{II}), C_{e}$ $(\mathrm{mg} / \mathrm{L})$ is the solution equilibrium concentration of $\mathrm{Pb}(\mathrm{II})$, $q_{\max }(\mathrm{mg} / \mathrm{g})$ is the maximum amount of $\mathrm{Pb}(\mathrm{II})$ which can be taken up by the sorbent, and $K_{\mathrm{L}}\left(\mathrm{L} \mathrm{mg}^{-1}\right)$ is the Langmuir 
TABLE 3: Effect of contact time on sorption capacity and percent extraction of lead by hybrid sorbents and biosorbents in pH 2.0 and 7.0 solutions.

\begin{tabular}{|c|c|c|c|c|c|c|}
\hline \multirow{2}{*}{$\mathrm{pH}$} & \multirow{2}{*}{ Min } & \multicolumn{5}{|c|}{ Metal capacity in $\mu \mathrm{mol} \mathrm{g}^{-1}$ (percent extraction)* } \\
\hline & & Ox-AC & Ox-AC-BY & Rd-AC & Rd-AC-BY & $\mathrm{AC}-\mathrm{BY}$ \\
\hline \multirow{7}{*}{2.0} & 1 & $20(21.0 \%)$ & $210(79.0 \%)$ & $100(64.5 \%)$ & $190(84.4 \%)$ & $290(93.5 \%)$ \\
\hline & 5 & $55(58.0 \%)$ & $215(81.0 \%)$ & $120(77.4 \%)$ & $190(84.4 \%)$ & $290(93.5 \%)$ \\
\hline & 10 & $75(79.0 \%)$ & $255(85.0 \%)$ & $130(84.0 \%)$ & $205(91.0 \%)$ & $300(96.8 \%)$ \\
\hline & 15 & $85(89.0 \%)$ & $230(86.8 \%)$ & $145(93.5 \%)$ & $210(93.0 \%)$ & $300(96.8 \%)$ \\
\hline & 20 & $95(100.0 \%)$ & $255(96.0 \%)$ & $150(96.7 \%)$ & $225(100.0 \%)$ & $310(100.0 \%)$ \\
\hline & 25 & 95 (100.0\%) & $265(100 \%)$ & $155(100 \%)$ & $225(100 \%)$ & $310(100.0 \%)$ \\
\hline & 30 & $95(100.0 \%)$ & $265(100.0 \%)$ & $155(100.0 \%)$ & $225(100.0 \%)$ & $310(100.0 \%)$ \\
\hline \multirow{7}{*}{7.0} & 1 & $150(75.0 \%)$ & $450(85.0 \%)$ & $245(87.5 \%)$ & $320(82.0 \%)$ & $310(86.1 \%)$ \\
\hline & 5 & $160(80 \%)$ & $425(87.0 \%)$ & $250(89.0 \%)$ & 335 (86.0\%) & $320(88.9 \%)$ \\
\hline & 10 & $175(87.5 \%)$ & $435(88.0 \%)$ & $255(91.0 \%)$ & $340(87.0 \%)$ & $340(94.4 \%)$ \\
\hline & 15 & $190(95.0 \%)$ & $440(86.8 \%)$ & $255(91.0 \%)$ & $365(93.6 \%)$ & $350(97.2 \%)$ \\
\hline & 20 & $200(100.0 \%)$ & $470(94.0 \%)$ & $265(94.6 \%)$ & $375(96.0 \%)$ & $360(100.0 \%)$ \\
\hline & 25 & $200(100.0 \%)$ & $470(94.0 \%)$ & $280(100.0 \%)$ & $385(98.7 \%)$ & $360(100.0 \%)$ \\
\hline & 30 & $200(100.0 \%)$ & $500(100.0 \%)$ & $280(100.0 \%)$ & $390(100.0 \%)$ & $360(100.0 \%)$ \\
\hline
\end{tabular}

${ }^{*}$ Values are based on $n=3$ with standard deviation of $2.0-5.0 \%$.

constant. On the other hand, the linearized Freundlich expression is given by (3):

$$
q_{e}=\log K_{\mathrm{F}}+\frac{1}{n} \log C_{e}
$$

where $K_{\mathrm{F}}$ and $1 / n$ are the Freundlich constants. The BraunerEmmet-Teller (BET) isotherm model proposes that the initial sorbed layer can act as a substrate for further sorption; then the isotherm, instead of leveling off to some saturated value at high concentrations, will be able to increase indefinitely. The simplified form of nonlinear form of BET is generally expressed by the following equation:

$$
q_{e}=\frac{q_{\max } K_{\mathrm{B}}}{\left(C_{s}-C\right)\left[1+\left(K_{\mathrm{B}}-1\right) \cdot C / C_{s}\right]} \cdot C_{e},
$$

where $q_{e}$ is the amount of sorbed $\mathrm{Pb}(\mathrm{II})$ per unit weight of activated carbon, $C_{e}$ is the equilibrium concentration of $\mathrm{Pb}(\mathrm{II})$ in solution $(\mathrm{mg} / \mathrm{L}$ or $\mathrm{mol} / \mathrm{L}), C_{s}$ is the saturation concentration of the $\mathrm{Pb}(\mathrm{II})$, and $K_{\mathrm{B}}$ is a constant (function of energy of adsorption and temperature).

Therefore, these three models have been used and applied to study and evaluate the sorption isotherms of lead by hybrid chemically and biologically modified active carbon. Figure 3 shows Langmuir's adsorption isotherms of lead by the various hybrid active carbon sorbents and biosorbents. Straight lines were obtained in all cases indicating that sorption processes of lead by the studied sorbents and biosorbents were obeying Langmuir's adsorption isotherm model and the determined Langmuir's parameters are listed in Table 4 . The high values of Langmuir's parameter, $q_{\max }$, are clearly giving excellent evidences for the favorable sorption of lead by modified sorbents and biosorbents (Ox-AC, Rd-AC, Ox-AC-BY, and Rd-AC-BY).

In addition, the application of Brauner-Emmet-Teller (BET) isotherm model to the process of lead sorption by
TABLE 4: The calculated Langmuir's parameters.

\begin{tabular}{lcc}
\hline Adsorbent & $q_{\max }$ & $K_{\mathrm{L}}$ \\
\hline Ox-AC & 167 & $5.35236 E-05$ \\
Rd-AC & 10000 & $1.45138 E-06$ \\
Ox-AC-BY & 200 & $3.17259 E-05$ \\
Rd-AC-BY & 250 & $5.95061 E-05$ \\
\hline
\end{tabular}

hybrid chemically and biologically modified active carbon sorbents and biosorbents was also studied. The collected results from applications of this model are represented by Figure 4 and clearly denote to the possible sorption of lead on the surface of these sorbents according to the postulates of BET adsorption models $[38,39]$.

3.2.4. The Effect of Sorbent Dose. The effect of sorbents and biosorbents dose was also studied as an important parameter to identify the relationship between lead sorption and mass of chemically and biologically modified sorbents. Figure 5 represents such relationship between sorbent mass versus percent extraction of lead. It is evident from Figure 5 that the percentage extraction values of $\mathrm{Pb}$ (II) from aqueous solutions by all studied sorbents and biosorbents increase with the increase in the applied and selected mass. This trend is mainly due to the presence of more active surface sites and functional groups available to bind with $\mathrm{Pb}$ (II). The yeast-modified biosorbents, $\mathrm{Ox}-\mathrm{CY}$ and $\mathrm{Rd}-\mathrm{CY}$, were found to exhibit their maximum percentage extraction values of $\mathrm{Pb}$ (II) ( 100\%) in presence of sorbent mass of $\geq 100 \mathrm{mg}$ owing to the possible surface saturation of these sorbents with $\mathrm{Pb}(\mathrm{II})$. On the other hand, chemically modified $\mathrm{Ox}-\mathrm{AC}$ and Rd-AC sorbents exhibited surface unsaturation trends upon their reactions with $\mathrm{Pb}$ (II) judging from the obtained straight lines [40]. 




(a)



(c)



(b)

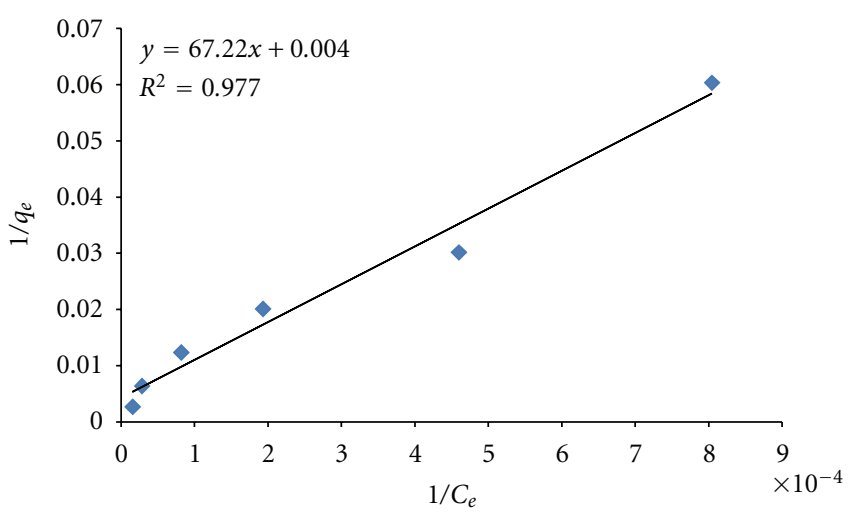

(d)

FIGURE 3: Langmuir's adsorption isotherms of lead sorption by hybrid active carbons (a) Ox-AC, (b) Ox-AC-BY, (c) Rd-AC and (d) Rd-ACBY.



(a)

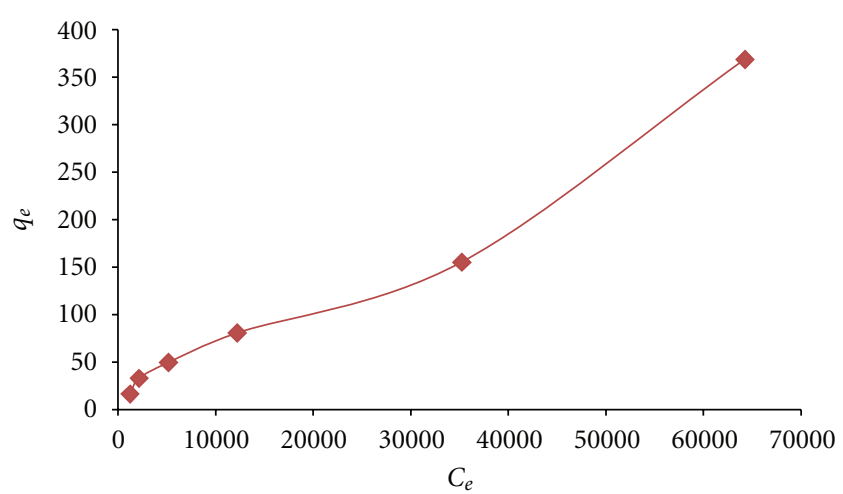

(b)

FIgURE 4: BET adsorption isotherms of lead sorption by hybrid active carbons (a) Ox-AC-BY and (b) Rd-AC-BY.

3.2.5. The Effect of Foreign Ions. The interference of some foreign cations such as $\mathrm{Co}(\mathrm{II}), \mathrm{Cu}(\mathrm{II}), \mathrm{Ni}(\mathrm{II})$, and $\mathrm{K}(\mathrm{I})$ as well as anions $\left(\mathrm{NO}_{3}{ }^{-}, \mathrm{Cl}^{-}\right.$, and acetate) on the process of lead extraction from aqueous solutions was studied and evaluated by all chemically and biologically treated active carbon sorbents and biosorbents. Evaluation of the possible interference of foreign ions was performed on the basis of equimolar concentration of lead acetate trihydrate versus other interfering species. The determined metal capacity values of lead in presence of these interfering anions and cations are listed in Table 5 along with those determined for lead capacity (Section 3.2). The existence of $\mathrm{KNO}_{3}$ and $\mathrm{NaCl}$ was characterized by low or no interfering effect in the sorption processes of lead by hybrid chemically and biologically modified active carbon sorbents and biosorbents. $\mathrm{Ni}(\mathrm{OAc})_{2}$ was found to exhibit low interfering effect owing to the determined metal capacity values of lead with respect to hybrid Ox-AC-BY and Rd-AC-BY biosorbents. $\mathrm{CoCl}_{2}$ and $\mathrm{CuCl}_{2}$ were found to show high interfering impact on the process of lead sorption by all modified active carbon 
TABLE 5: Effect of foreign ions on the metal capacity values of lead.

\begin{tabular}{lccccccc}
\hline \multirow{2}{*}{ Adsorbent } & \multirow{2}{*}{$\mathrm{pH}$} & $\mathrm{KNO}_{3}$ & $\mathrm{NaCl}$ & $\mathrm{Ni}(\mathrm{AcO})_{2}$ & $\mathrm{CoCl}_{2}$ & $\mathrm{CuCl}_{2}$ & $\left.\mathrm{~Pb}^{2} \mathrm{AC}\right)_{2}$ \\
\hline Ox-AC & 7.0 & 195 & 235 & 290 & 87 & 127 & 200 \\
Rd-AC & 7.0 & 250 & 200 & 265 & 121 & 212 & 280 \\
Ox-AC-BY & 7.0 & 480 & 510 & 299 & 126 & 290 & 500 \\
Rd-AC-BY & 7.0 & 350 & 400 & 309 & 183 & 290 & 390 \\
\hline
\end{tabular}

* Values are based on $n=3$ with standard deviation of $2.0-5.0 \%$.

TABLE 6: Removal of lead from real water samples by modified AC.

\begin{tabular}{|c|c|c|c|c|c|}
\hline \multirow{2}{*}{ Water sample } & \multirow{2}{*}{ Sorbent } & \multirow{2}{*}{ Sorbent mass } & \multirow{2}{*}{ Spiked (ppm) } & \multicolumn{2}{|c|}{ \% Extraction } \\
\hline & & & & 1st stage & 2nd stage \\
\hline \multirow{5}{*}{ Drinking tap water } & $\mathrm{AC}$ & & \multirow{5}{*}{1.900} & $29.0 \%$ & $70.0 \%$ \\
\hline & Ox-AC & & & $86.0 \%$ & $91.8 \%$ \\
\hline & Rd-AC & & & $80.5 \%$ & $85.0 \%$ \\
\hline & Ox-AC-BY & & & $92.0 \%$ & $99.0 \%$ \\
\hline & Rd-AC-BY & $200 \mathrm{mg}$ & & $91.0 \%$ & $95.7 \%$ \\
\hline \multirow{4}{*}{ Agricultural waste water } & Ox-AC & & \multirow{4}{*}{1.590} & $66.0 \%$ & $87.0 \%$ \\
\hline & Rd-AC & & & $62.0 \%$ & $83.0 \%$ \\
\hline & Ox-AC-BY & & & $75.0 \%$ & $95.0 \%$ \\
\hline & Rd-AC-BY & & & $77.0 \%$ & $97.0 \%$ \\
\hline
\end{tabular}

* \% Extraction values are based on $n=3$ with standard deviation of 3.0-5.0\%.

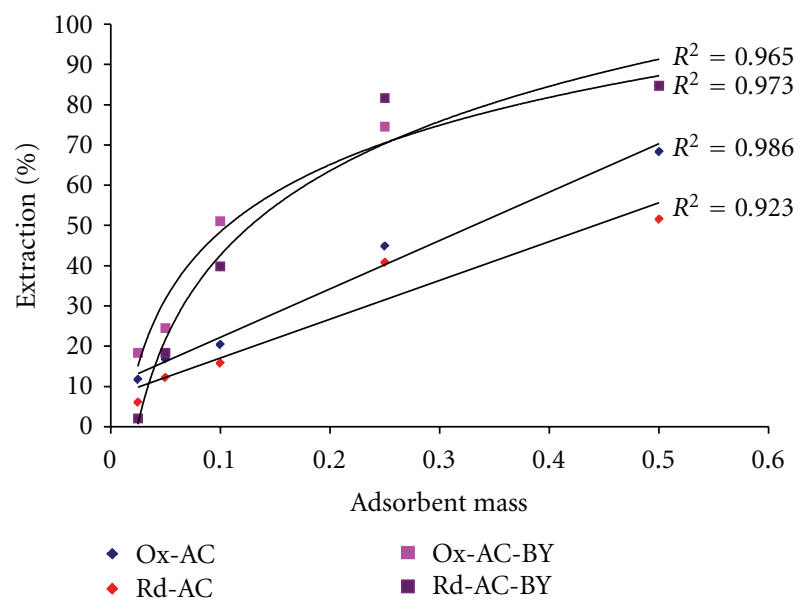

Figure 5: Effect of sorbent dose on $\mathrm{Pb}$ (II) sorption.

sorbents. In the case of $\mathrm{Ox}-\mathrm{AC}$ and $\mathrm{Rd}-\mathrm{AC}$ sorbents, the capacity values of lead in presence of $\mathrm{CoCl}_{2}$ was found to decrease from 200 and $280 \mu \mathrm{mol} \mathrm{g}^{-1}$ to 87 and $121 \mu \mathrm{mol} \mathrm{g}^{-1}$, respectively, while in the case of $\mathrm{CuCl}_{2}$, these were found to reach 127 and $212 \mu \mathrm{mol} \mathrm{g}^{-1}$, respectively. In addition, $\mathrm{CoCl}_{2}$ and $\mathrm{CuCl}_{2}$ were also characterized by high capability of direct interference in lead sorption processes by other modified AC sorbents, Ox-AC-BY and Rd-AC-BY, judging from the listed $\mu \mathrm{mol} \mathrm{g}^{-1}$ capacity values in Table 5 . Thus, one can easily conclude that a strong competition between $\mathrm{Pb}$ (II), $\mathrm{Co}(\mathrm{II})$, and $\mathrm{Cu}$ (II) for binding with the active sites and functional groups loaded on the surface of chemically and biologically modified active carbon sorbents and biosorbents.
3.3. Applications of Hybrid AC Sorbents and Biosorbents for Extraction and Removal of Pb(II) from Water Samples. The capability of hybrid chemically and biologically modified active carbon sorbents and biosorbents to extract $\mathrm{Pb}$ (II) from real water samples (drinking tap water and Agricultural waste water) was further studied as the final step to explore the potential applications of these sorbents and biosorbents in water treatment and purification. Table 6 compiles the results of metal removal and extraction via applications of a double-stage microcolumn technique. It is evident from the listed data that chemically modified active carbon sorbents are lower in their metal binding properties than other biologically modified biosorbents and both of them are higher than the blank AC sorbent. The application of AC sorbent as a packing material in a microcolumn extraction was found to produce a percentage extraction value of $70.0 \%$ after two runs of drinking tap water through the microcolumn. On the other hand, Ox-AC, Rd-AC, Ox-AC-BY, and Rd-AC-BY were found to produce percentage extraction values of 86.0 , $80.5,92.0$, and $91.0 \%$, respectively, for the first run. The second run was found to offer higher percentage extraction values of 91.8, 85.0, 99.0, and 95.7 for the same sorbents and biosorbents. The same trend and behavior were also identified when these modified sorbents and biosorbents were applied for lead removal from Agricultural waste water samples by producing percentage extraction values of the first run as 66.0, 62.0, 75.0, and 75.0 for Ox-AC, Rd-AC, OxAC-BY, and Rd-AC-BY, respectively. These values were found to increase when the second run was performed to produce 87.0, 83.0, 95.0, and 97.0\%. Thus, it is important to point out here to the pronounced contribution of redox chemical treatments as well as surface immobilization of baker's yeast 
in the process of lead extraction and removal from the two examined water samples. The percentage extraction and removal values were found in the range of 95.7-99.0\% for hybrid chemically and biologically modified Ox-AC-BY and Rd-AC-BY biosorbents. In addition, practical applications of double-stage microcolumn approach in lead(II) purification from water samples were also characterized and identified by providing excellent recovery results in the treatment process compared to single-stage microcolumn analysis.

\section{Conclusion}

Several major findings and conclusions can be withdrawn from this study and these can be summarized in the following points. First, chemical treatments of commercial active carbon via simple oxidation and reduction reactions were found to improve the sorption efficiency and uptake of the chemically modified AC sorbents for lead. Second, oxidized active carbon-modified-baker's yeast biosorbent was characterized by its excellent sorption efficiency under the effect of all studied controlling factors compared to other chemically and biologically modified active carbon sorbents and biosorbents. Third, the equilibrium sorption of lead by chemically and biologically treated active carbon sorbents and biosorbents was found to follow typical adsorption isotherms and fitted well with both the Langmuir and BET adsorption isotherm models. Fourth, the determined lead sorption capacity values by chemically and biologically treated active carbon sorbents and biosorbents are higher compared to other previously reported methods. Fifth, excellent percentage recovery values of lead were obtained by the application of a double stage microcolumn separation technique.

\section{Conflict of Interests}

The authors of this manuscript declare that there is no conflict of interests with any identities mentioned in this work.

\section{Acknowledgment}

The authors would gratefully acknowledge the financial support from NSF award no. 0959807.

\section{References}

[1] W. Lo, H. Chua, K. H. Lam, and S. P. Bi, "A comparative investigation on the biosorption of lead by filamentous fungal biomass," Chemosphere, vol. 39, no. 15, pp. 2723-2736, 1999.

[2] M. Nadeem, A. Mahmood, S. A. Shahid, S. S. Shah, A. M. Khalid, and G. McKay, "Sorption of lead from aqueous solution by chemically modified carbon adsorbents," Journal of Hazardous Materials B, vol. 138, no. 3, pp. 604-613, 2006.

[3] O. Gercel and H. F. Gerçel, "Adsorption of lead(II) ions from aqueous solutions by activated carbon prepared from biomass plant material of Euphorbia rigida," Chemical Engineering Journal, vol. 132, no. 1-3, pp. 289-297, 2007.

[4] M. E. Mahmoud, M. M. Osman, O. F. Hafez, A. H. Hegazi, and E. Elmelegy, "Removal and preconcentration of lead (II) and other heavy metals from water by alumina adsorbents developed by surface-adsorbed-dithizone," Desalination, vol. 251, no. 1-3, pp. 123-130, 2010.

[5] M. Imamoglu and O. Tekir, "Removal of copper (II) and lead (II) ions from aqueous solutions by adsorption on activated carbon from a new precursor hazelnut husks," Desalination, vol. 228, pp. 108-113, 2008.

[6] S. Wang, Q. Ma, and Z. H. Zhu, "Characteristics of unburned carbons and their application for humic acid removal from water," Fuel Processing Technology, vol. 90, pp. 375-380, 2009.

[7] K. B. Payne and T. M. Abdel-Fattah, "Adsorption of divalent lead ions by zeolites and activated carbon: effect of $\mathrm{pH}$, temperature, and Ionic strength," Journal of Environmental Science and Health A, vol. 39, pp. 2275-2291, 2004.

[8] H. Lalhruaitluanga, K. Jayaram, M. N. V. Prasad, and K. K. Kumar, "Lead(II) adsorption from aqueous solutions by raw and activated charcoals of Melocanna baccifera Roxburgh (bamboo)-a comparative study," Journal of Hazardous Materials, vol. 175, no. 1-3, pp. 311-318, 2010.

[9] M. Machida, T. Mochimaru, and H. Tatsumoto, "Lead(II) adsorption onto the graphene layer of carbonaceous materials in aqueous solution," Carbon, vol. 44, no. 13, pp. 2681-2688, 2006.

[10] E. A. El-Sofany, W. F. Zaher, and H. F. Aly, "Sorption potential of impregnated charcoal for removal of heavy metals from phosphoric acid," Journal of Hazardous Materials, vol. 165, no. 1-3, pp. 623-629, 2009.

[11] Y. Li, Q. Du, X. Wang et al., "Removal of lead from aqueous solution by activated carbon prepared from Enteromorpha prolifera by zinc chloride activation," Journal of Hazardous Materials, vol. 183, no. 1-3, pp. 583-589, 2010.

[12] L. Wang, J. Zhang, R. Zhao, Y. Li, C. Li, and C. Zhang, "Adsorption of $\mathrm{Pb}(\mathrm{II})$ on activated carbon prepared from Polygonum orientale Linn.: kinetics, isotherms, $\mathrm{pH}$, and ionic strength studies," Bioresource Technology, vol. 101, no. 15, pp. 5808-5814, 2010.

[13] F. Boudrahem, F. Aissani-Benissad, and H. Ait-Amar, "Batch sorption dynamics and equilibrium for the removal of lead ions from aqueous phase using activated carbon developed from coffee residue activated with zinc chloride," Journal of Environmental Management, vol. 90, no. 10, pp. 3031-3039, 2009.

[14] J. Acharya, J. N. Sahu, C. R. Mohanty, and B. C. Meikap, "Removal of lead(II) from wastewater by activated carbon developed from Tamarind wood by zinc chloride activation," Chemical Engineering Journal, vol. 149, no. 1-3, pp. 249-262, 2009.

[15] C. K. Singh, J. N. Sahu, K. K. Mahalik, C. R. Mohanty, B. R. Mohan, and B. C. Meikap, "Studies on the removal of $\mathrm{Pb}$ (II) from wastewater by activated carbon developed from Tamarind wood activated with sulphuric acid," Journal of Hazardous Materials, vol. 153, no. 1-2, pp. 221-228, 2008.

[16] M. Imamoglu and O. Tekir, "Removal of copper (II) and lead (II) ions from aqueous solutions by adsorption on activated carbon from a new precursor hazelnut husks," Desalination, vol. 228, no. 1-3, pp. 108-113, 2008.

[17] G. Issabayeva, M. K. Aroua, and N. M. N. Sulaiman, "Removal of lead from aqueous solutions on palm shell activated carbon," Bioresource Technology, vol. 97, no. 18, pp. 23502355, 2006.

[18] M. Sekar, V. Sakthi, and S. Rengaraj, "Kinetics and equilibrium adsorption study of lead(II) onto activated carbon prepared from coconut shell," Journal of Colloid and Interface Science, vol. 279, no. 2, pp. 307-313, 2004. 
[19] M. Machida, Y. Kikuchi, M. Aikawa, and H. Tatsumoto, "Kinetics of adsorption and desorption of $\mathrm{Pb}$ (II) in aqueous solution on activated carbon by two-site adsorption model," Colloids and Surfaces A, vol. 240, no. 1-3, pp. 179-186, 2004.

[20] D. J. Malik, V. Strelko Jr., M. Streat, and A. M. Puziy, "Characterisation of novel modified active carbons and marine algal biomass for the selective adsorption of lead," Water Research, vol. 36, no. 6, pp. 1527-1538, 2002.

[21] Y. H. Li, Z. Di, J. Ding, D. Wu, Z. Luan, and Y. Zhu, "Adsorption thermodynamic, kinetic and desorption studies of $\mathrm{Pb}^{2+}$ on carbon nanotubes," Water Research, vol. 39, no. 4, pp. 605-609, 2005.

[22] E. Pehlivan and G. Arslan, "Removal of metal ions using lignite in aqueous solution-Low cost biosorbents," Fuel Processing Technology, vol. 88, pp. 99-106, 2007.

[23] B. Wang, W. Li, H. Chen, B. Li, and G. Wang, "The removal of mercury from coal via sub-critical water extraction," Fuel Processing Technology, vol. 87, no. 5, pp. 443-448, 2006.

[24] C. Arpa, E. Basyilmaz, S. Bektas, O. Genc, and Y. Yurum, "Cation exchange properties of low rank Turkish coals: removal of $\mathrm{Hg}, \mathrm{Cd}$ and $\mathrm{Pb}$ from waste water," Fuel Processing Technology, vol. 68, pp. 111-120, 2000.

[25] M. E. Mahmoud, M. M. Osman, O. F. Hafez, and E. Elmelegy, "Removal and preconcentration of lead (II), copper (II), chromium (III) and iron (III) from wastewaters by surface developed alumina adsorbents with immobilized 1-nitroso-2naphthol," Journal of Hazardous Materials, vol. 173, no. 1-3, pp. 349-357, 2010.

[26] M. E. Mahmoud, A. A. Yakout, and M. M. Osman, "Dowex anion exchanger-loaded-baker's yeast as bi-functionalized biosorbents for selective extraction of anionic and cationic mercury(II) species," Journal of Hazardous Materials, vol. 164, no. 2-3, pp. 1036-1044, 2009.

[27] B. Godlewska-Zyłkiewicz and M. Kozłowska, "Solid phase extraction using immobilized yeast Saccharomyces cerevisiae for determination of palladium in road dust," Analytica Chimica Acta, vol. 539, no. 1-2, pp. 61-67, 2005.

[28] A. A. Menegário, A. J. Silva, E. Pozzi, S. F. Durrant, and C. H. Abreu Jr., "On-line determination of Sb(III) and total $\mathrm{Sb}$ using baker's yeast immobilized on polyurethane foam and hydride generation inductively coupled plasma optical emission spectrometry," Spectrochimica Acta B, vol. 61, no. 9, pp. 1074-1079, 2006.

[29] H. Bag, A. R. Türker, M. Lale, and A. Tunçeli, "Separation and speciation of $\mathrm{Cr}(\mathrm{III})$ and $\mathrm{Cr}(\mathrm{VI})$ with Saccharomyces cerevisiae immobilized on sepiolite and determination of both species in water by FAAS," Talanta, vol. 51, no. 5, pp. 895-902, 2000.

[30] G. G. R. Ghezelbash, F. Marahel, S. Ehsanipour, A. Najibi, M. Soylak, and M. Ghaedi, "Equilibrium, thermodynamic, and kinetic studies on lead (II) biosorption from aqueous solution by Saccharomyces cerevisiae biomass," CLEAN-Soil, Air, Water, vol. 38, no. 9, pp. 877-885, 2010.

[31] A. A. Menegário, P. Smichowski, and G. Polla, "On-line preconcentration and speciation analysis of $\mathrm{Cr}(\mathrm{III})$ and $\mathrm{Cr}(\mathrm{VI})$ using baker's yeast cells immobilised on controlled pore glass," Analytica Chimica Acta, vol. 546, no. 2, pp. 244-250, 2005.

[32] S. Baytak and A. R. Türker, "The use of Agrobacterium tumefacients immobilized on Amberlite XAD-4 as a new biosorbent for the column preconcentration of iron(III), cobalt(II), manganese(II) and chromium(III)," Talanta, vol. 65, no. 4, pp. 938-945, 2005.

[33] M. M. Osman, S. A. Kholeif, N. A. Abou Al-Maaty, and M. E. Mohmoud, "Metal sorption, solid phase extraction and preconcentration properties of two silica gel phases-chemically immobilized-2-hydroxynaphthaldehyde," Mikrochimica Acta, vol. 143, pp. 25-31, 2003.

[34] M. E. Mahmoud, A. A. Soayed, and O. F. Hafez, "Selective solid phase extraction and pre-concentration of heavy metals from sea water by silica gel phases-physically and chemically immobilized-4-amino-3-hydroxy-2(2-chloro-benzene)azo-1-naphthalene sulfonic acid," Microchimica Acta, vol. 143, no. 1, pp. 65-70, 2003.

[35] M. E. Mahmoud, M. S. Masoud, and N. N. Maximous, "Synthesis, characterization and selective metal binding properties of physically adsorbed 2-thiouracil on the surface of porous silica and alumina," Microchimica Acta, vol. 147, no. 1-2, pp. 111-115, 2004.

[36] R. Baccara, J. Bouzida, M. Fekib, and A. Montiela, "Preparation of activated carbon from Tunisian olive-waste cakes and its application for adsorption of heavy metal ions," Journal of Hazardous Materials, vol. 162, no. 2-3, pp. 1522-1529, 2009.

[37] W. Oh, C. Park, and C. Lim, "Physical properties of KPACFs and their $\mathrm{pH}$ dependence on their T-N and T-P removal," Journal of Ceramic Processing Research, vol. 7, no. 4, pp. 315320, 2006.

[38] K. B. Payne and T. M. Abdel-Fattah, "Adsorption of arsenate and arsenite by iron-treated activated carbon and zeolites: effects of $\mathrm{pH}$, temperature, and ionic strength," Journal of Environmental Science and Health A, vol. 40, no. 4, pp. 723$749,2005$.

[39] C. Faur-Brasquet, K. Kadirvelu, and P. Le Cloirec, "Removal of metal ions from aqueous solution by adsorption onto activated carbon cloths: Adsorption competition with organic matter," Carbon, vol. 40, no. 13, pp. 2387-2392, 2002.

[40] J. Li, J. Hu, G. Sheng, G. Zhao, and Q. Huang, "Effect of pH, ionic strength, foreign ions and temperature on the adsorption of $\mathrm{Cu}$ (II) from aqueous solution to GMZ bentonite," Colloids and Surfaces A, vol. 349, pp. 195-201, 2009. 


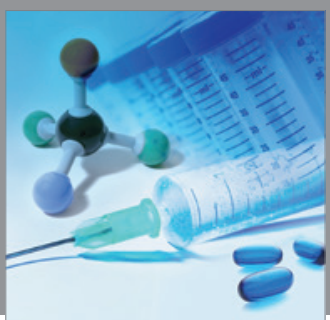

International Journal of

Medicinal Chemistry

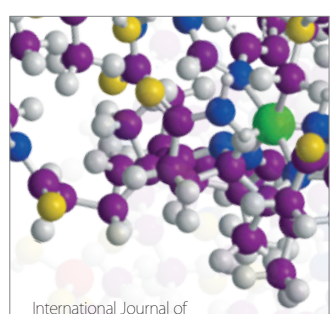

Carbohydrate Chemistry

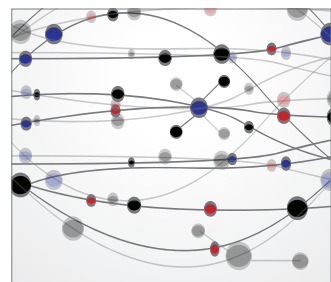

The Scientific World Journal
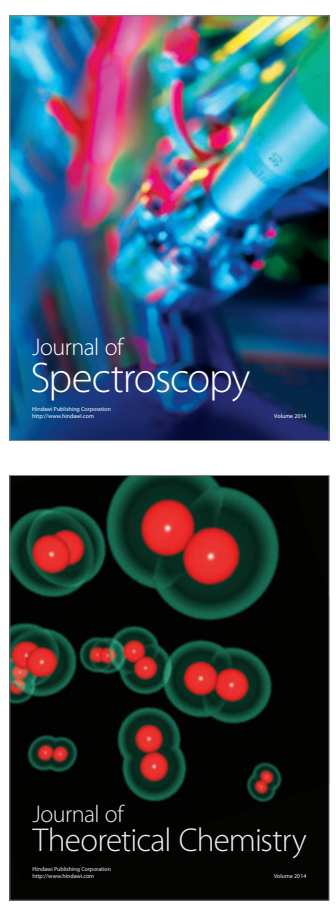
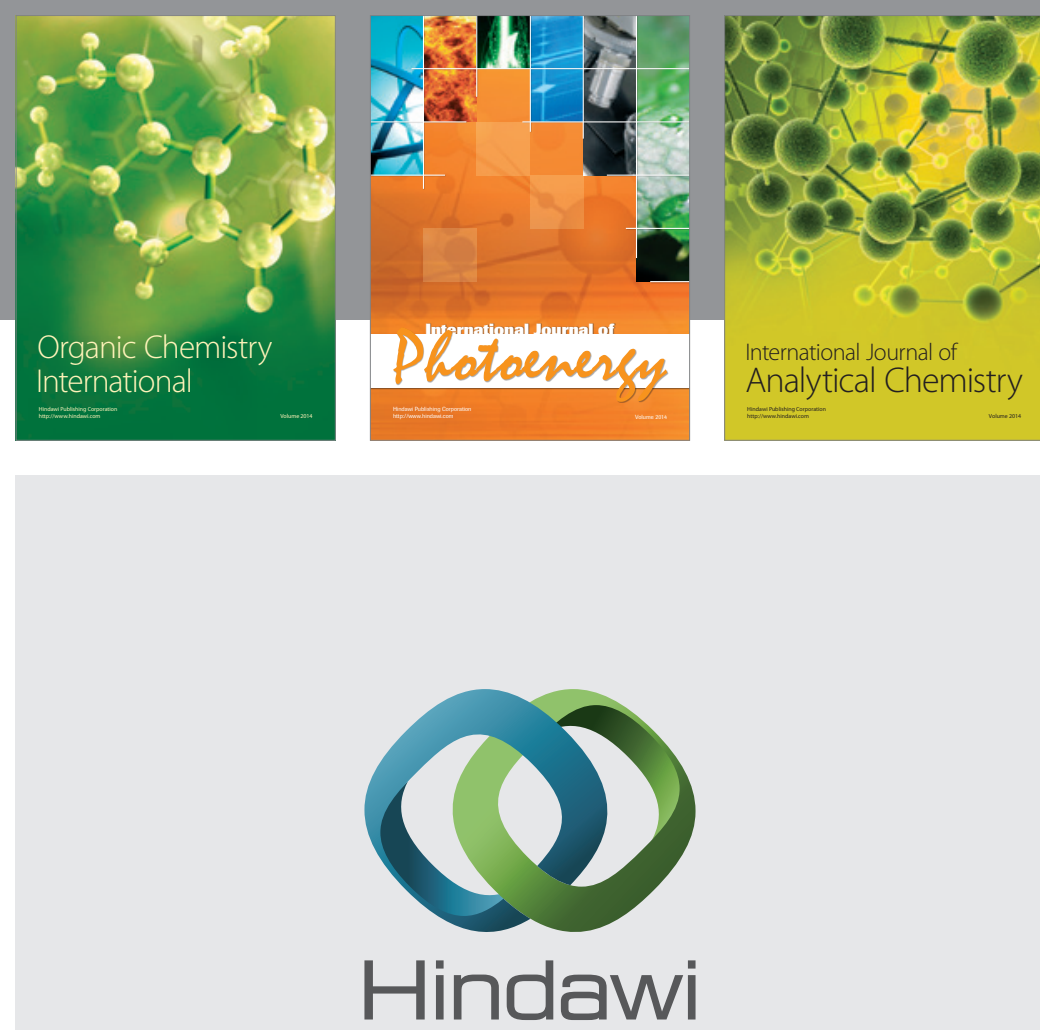

Submit your manuscripts at

http://www.hindawi.com


Journal of

Applied Chemistry
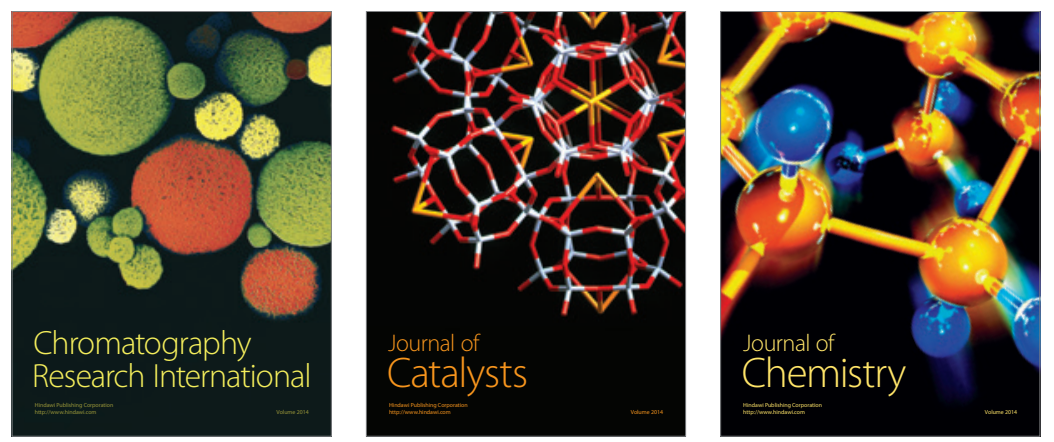
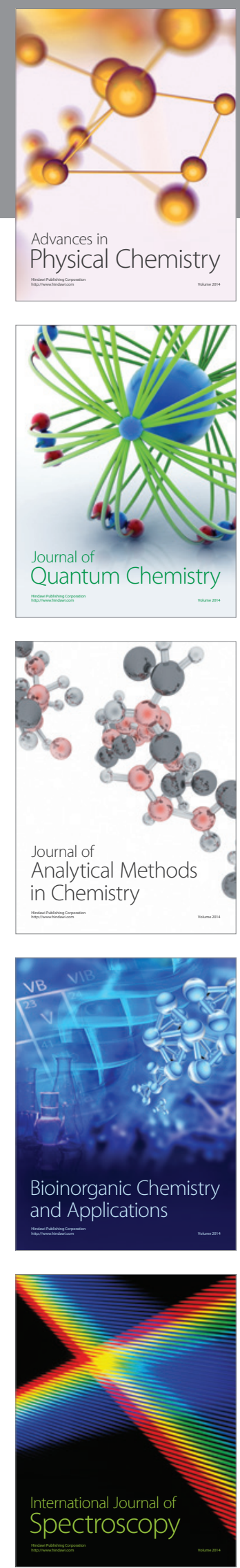